\title{
MAINTENANCE OF THE COAL SAMPLE BANK AND DATABASE
}

\author{
Quarterly Technical Progress Report
}

Contract Number DE-AC22-93PC93051

The Pennsylvania State University

Coal and Organic Petrology Laboratories

Reporting Period: 1/01/95 - 3/31/95

Report Date: $8 / 25 / 95$

Contract Date: $9 / 28 / 93$

Anticipated Completion Date: 9/28/98

Government Award: $\$ 173,843$. for current contract year

Principal Investigators: Alan Davis

David C. Glick

Program Manager: Gilbert V. McGurl

Contracting Officer's Representative: Udaya Rao
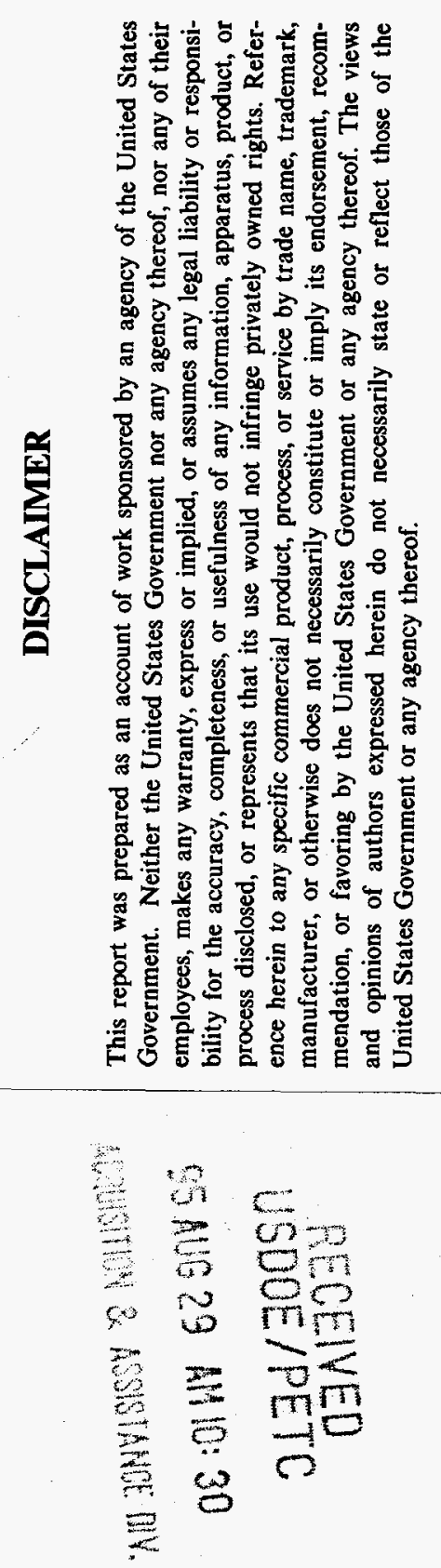

US/DOE Patent Clearance is not required prior to the publication of this document. 


\section{DISCLAIMER}

Portions of this document may be illegible in electronic image products. Images are produced from the best available original document. 
Quarterly Technical Progress Report: 1/01/95 - 3/31/95

Objectives: NUMBER OF SAMPLES?? OTHER CHANGES??

This five year project is intended to ensure the availability of wellcharacterized, high-quality coal samples for public and private coal research. It continues support of the DOE Coal Sample Bank and Database at The Pennsylvania State University. Thirty coal samples will be collected, processed, packaged, and analyzed, and a resulting database will be maintained. These samples and data, as well as 26 samples collected under previous contracts, will be distributed to DOE contractors and others performing coal research.

Samples will be chosen to maintain a sample bank of 56 coals representing the major. U.S. coal fields and a variety of coal ranks and compositions. In addition to standard analyses, liquefaction tests and organic geochemical analyses will be performed. The samples will be stored to minimize deterioration, and will be monitored annually by proximate, sulfur forms, and gaseous oxygen analysis to evaluate their condition. These samples will be used for additional research on the influence of changes in surface chemistry on surface properties, the influence of sample deterioration on liquefaction properties, and the mechanisms of coal oxidation.

\section{Summary of Technical Progress}

Task 1B. Storage and Inventory of Samples

All samples supported by the contract are stored in containers purged with argon before sealing; container locations are tracked by a computer inventory program. PSOC-series samples are stored in drums or buckets at the Coal Sample Bank building, or in cans in the Coal and Organic Petrology Laboratories. All DECSseries samples are stored under refrigeration in foil laminate bags.

During the quarter, samples were distributed and inventory records were updated. Storage and inventory of sample containers is expected to continue routinely through the next quarter.

Task 1C. Monitoring of Sample Quality

It was planned that one $300 \mathrm{~g}(2 / 3 \mathrm{lb})$ bag of each DECS sample will be analyzed annually to monitor sample condition. This Task has been reduced in scope because of reduction in funding.

Ten samples were selected for monitoring. The first samples analyzed were DECS-23 and DECS-24, in order that the results would coincide with those from liquefaction monitoring (in Task 1F). Results will be reported when work is completed.

Task 1D. Collection and Processing of Replacement Samples

Processing of the most recently collected samples (DECS-24 through -28) through the step of packaging at minus 20 mesh was completed during the quarter. Collection of new samples is anticipated for the next quarter. Processing of 
previously collected DECS samples to -60 mesh 75 gram bags was begun and will continue for several quarters.

Task 1E. Basic Characterization of Coal Samples

Characterization of samples DECS-24 through -28 continued; analyses of inorganic constituents were completed during the quarter.

Task 1F. Liquefaction Testing

In this Task, appropriate samples will be subjected to a standardized liquefaction test using tetralin and subsequent product workup.

A protocol was developed and splits of samples DECS-23 and -24 were set aside for the planned time study of liquefaction behavior as related to storage conditions, which will be performed annually in conjunction with the monitoring of sample quality (Task $1 \mathrm{C}$ ). Annual liquefaction runs will be performed on:

1) splits remaining sealed in original foil laminate bags, under refrigeration;

2) splits exposed to the laboratory atmosphere, without refrigeration; and for samples other than DECS-24,

3) splits remaining sealed in original foil laminate bags, without refrigeration.

During the quarter, liquefaction runs and concurrent quality monitoring were performed to provide initial data for this study. Results will be reported when the remainder of the year's quality monitoring effort has been completed.

Task 1G. Investigation of Changes in Surface Chemistry During Storage

The general objective of this task is to measure the changes in functional group concentration as a function of duration and type of storage method using reflectance-mode FT-i.r. and direct oxygen determination using electron optical techniques. Also, microscopic measurements of fluorescence alteration and intensity will be employed to determine the extent of surface alteration during coal storage.

Further work on this Task has been suspended pending decisions on funding.

Task 1H. Organic Geochemistry

Nuclear Magnetic Resonance (NMR) Spectroscopy

Dried powdered samples of coal were placed in the bullet-type rotor of a Chemagnetics, Inc. M-100 NMR spectrometer and analyzed according to the crosspolarization, magic-angle spinning (CPMAS) and dipolar dephasing with magic angle spinning (DDMAS) procedures outlined by Hatcher (1988). For CPMAS, approximately 10,000 transients having a contact time of $1 \mathrm{~ms}$ and a cycle time of 1 $\mathrm{s}$ were acquired in $0.5 \mathrm{~K}$ of data, zero-filled to $4 \mathrm{~K}$. The chemical shifts were referenced to hexamethylbenzene. For DDMAS, approximately 8000 transients with a cycle time of $1 \mathrm{~s}$ were used at each of 10 dephasing times.

Effort during the quarter was concentrated on this Task. Table 1 shows structural parameters determined from DDMAS measurements, namely the fractions of 
protonated aromatic carbon and mobile methyl and quaternary aliphatic carbon, for 16 DECS coals studied during the quarter.

Bloch decay experiments were performed as described by Hatcher et al. (1992), principally to verify the spectra obtained by conventional CPMAS (presented in the last two quarterly progress reports). Approximately 2500 transients with a cycle time of $80 \mathrm{~s}$ were collected. The spectra are shown in Appendix A.

Table 1. Structural Parameters of DECS coals determined by DDMAS measurements

\begin{tabular}{|l|l|l|l|l|}
\hline $\begin{array}{l}\text { sample } \\
\text { DECS- }\end{array}$ & seam & rank & $\begin{array}{l}\text { aromatic } \\
\text { protonated C }\end{array}$ & $\begin{array}{l}\text { mobile } \mathrm{CH}_{3} \\
\text { and quaternary } \\
\text { aliphatic C }\end{array}$ \\
\hline 1 & Bottom & subC & 0.30 & 0.15 \\
\hline 2 & Illinois \#6 & hvCb & 0.55 & 0.48 \\
\hline 8 & Smith-Roland & subC & 0.28 & 0.35 \\
\hline 9 & Dietz & subB & 0.34 & 0.19 \\
\hline 11 & Beulah & ligA & 0.45 & 0.22 \\
\hline 12 & Pittsburgh & hvAb & 0.49 & 0.29 \\
\hline 13 & Sewell & mvb & 0.37 & 0.19 \\
\hline 17 & Blind Canyon & hvAb & 0.40 & 0.14 \\
\hline 18 & Kentucky \#9 & hvBb & 0.20 & 0.34 \\
\hline 23 & Pittsburgh & hvAb & 0.39 & 0.58 \\
\hline 24 & Illinois \#6 & hvCb & 0.15 & 0.39 \\
\hline 25 & Pust & ligA & 0.43 & 0.14 \\
\hline 26 & Wyodak & subB & 0.56 & 0.15 \\
\hline 27 & Deadman & subA & 0.37 & 0.16 \\
\hline 28 & Green & hvCb & 0.25 & 0.35 \\
\hline
\end{tabular}

Tables 2 and 3 summarize the composition of the pyrolysis products by type of compound for the three samples completed during the quarter. Table 2 shows results as percent of total gc-amenable products; Table 3 normalizes these results to percent of identified products. In each table, results are preliminary; more peaks may be identified in the future. Appendix $B$ contains the total ion chromatograms of the pyrolyzates produced from these samples. 
Table 2. Structural parameters determined by py/gc/ms (percent of total gc-amenable products). Results of preliminary identification of peaks.

\begin{tabular}{|l|l|l|c|c|c|c|}
\hline sample & seam & rank & $\begin{array}{l}\text { n-alkanes } \\
\text { and } \\
\text { alkenes }\end{array}$ & phenols & $\begin{array}{l}\text { non-oxygenated } \\
\text { aromatic } \\
\text { hydrocarbons }\end{array}$ & $\begin{array}{c}\text { unident- } \\
\text { ified }\end{array}$ \\
\hline DECS-1 & Bottom & subC & 39.2 & 8.3 & 37.1 & 15.4 \\
\hline DECS-9 & Dietz & subB & 34.9 & 17.3 & 6.7 & 41.1 \\
\hline DECS-11 & Beulah & lig & 37.3 & 17.8 & 27.9 & 17.0 \\
\hline DECS-13 & Sewell & mvb & 33.9 & 16.8 & 6.9 & 42.4 \\
\hline DECS-18 & Kentucky \#9 & hvBb & 41.5 & 22.3 & 7.6 & 28.6 \\
\hline DECS-19 & Pocahontas \#3 & Ivb-.. & 16.0 & 18.9 & 9.6 & 55.5 \\
\hline DECS-23 & Pittsburgh & hvAb & 39.3 & 38.5 & 9.0 & 13.2 \\
\hline
\end{tabular}

Table 3. Structural parameters determined by py/gc/ms (percent of identified products). Results of preliminary identification of peaks.

\begin{tabular}{|l|l|c|c|c|c|}
\hline sample & seam & rank & $\begin{array}{l}\text { n-alkanes } \\
\text { and } \\
\text { alkenes }\end{array}$ & phenols & $\begin{array}{l}\text { non-oxygenated } \\
\text { aromatic } \\
\text { hydrocarbons }\end{array}$ \\
\hline DECS-1 & Bottom & subC & 46.3 & 9.8 & 43.9 \\
\hline DECS-9 & Dietz & subB & 59.3 & 29.4 & 11.3 \\
\hline DECS-11 & Beulah & lig & 44.9 & 21.4 & 33.7 \\
\hline DECS-13 & Sewell & mvb & 58.8 & 29.2 & 12.0 \\
\hline DECS-18 & Kentucky \#9 & hvBb & 58.2 & 31.2 & 10.6 \\
\hline DECS-19 & Pocahontas \#3 & lvb & 36.0 & 42.4 & 21.6 \\
\hline DECS-23 & Pittsburgh & hvAb & 45.3 & 44.3 & 10.4 \\
\hline
\end{tabular}

Task 11. Distribution of Coal Samples to Users

During the period 1/01/95 - 3/31/95 a total of 37 samples (25 DOE Sample Bank samples and 12 other Penn State sample) of various sizes in 68 containers were distributed. See Task $2 \mathrm{C}$ for a list of sample and data recipients. This task will continue in the same manner through the next quarter.

Task 2A. Programming

Some changes to the sample container inventory program were undertaken during the quarter. 
Task 2B. Data Entry

Trace element analyses and other data produced for samples DECS-24 through -28 were added to the Database during the quarter.

Task 2C. Distribution of Data to Users

During the quarter a total of 150 data printouts were distributed. In addition, 19 special data requests were filled by database searches and printed output or creation of a data disk, resulting in distribution of limited information on 2530 samples. Preliminary requests for Sample Bank and Database information have also been filled. This task will continue in the same manner through the next quarter.

Organizations supplied with coal samples and/or data include:

Brigham Young University, Chemical Engineering Department

Buckeye Industrial Mining Company

Centre Lime \& Stone Company

City College of New York, Chemical Engineering Department

Clark Atlanta University, Chemistry Department

EER

Exxon Production Research Company

Geological Survey of Denmark

Hazen Research

Imperial College, Chemical Engineering Department (United Kingdom)

Jeffrey R. Levine, Consulting Geologist

Monash University, Chemistry Department (Australia) (2)

North Carolina A \& T State University, Mechanical Engineering Department (2)

Pennsylvania Department of Environmental Resources, Hawk Run Field Office

Pennsylvania Geological Survey

Pennsylvania State University, Energy and Fuels Research Center

Pennsylvania State University, Fuel Science Department (6)

Pennsylvania State University, Mineral Processing Department

Pennsylvania State University, Mining Engineering Department (2)

Pickands-Mather Coal Company

Southern Illinois University, Mechanical Engineering Department

University of Cincinnati, Chemical Engineering Department

University of Mississippi

University of Oklahoma

University of Oklahoma, Chemical Engineering and Materials Science Department

University of Tennessee at Knoxville, Geological Science Department

University of Utah, Chemistry Department

West Virginia University, Chemical Engineering Department

Western Research Institute

The numbers in parentheses represent multiple requests which were separately processed. 


\section{References}

Hatcher, P.G., 1988. Dipolar-dephasing ${ }^{13} \mathrm{C}$ NMR studies of decomposed wood and coalified xylem tissue: evidence for chemical structural changes associated with defunctionalization of lignin structural units during coalification. Energy \& Fuels, v. 2, pp 40-58.

Hatcher, P.G., Faulon, J.-L., Wenzel, K.A., and Cody, G.D., 1992. A structural Model for Lignin-Derived Vitrinite from High-Volatile Bituminous Coal (Coalified Wood). Energy \& Fuels, v. 6, pp 813-820. 
APPENDIX A. Bloch Decay NMR spectra

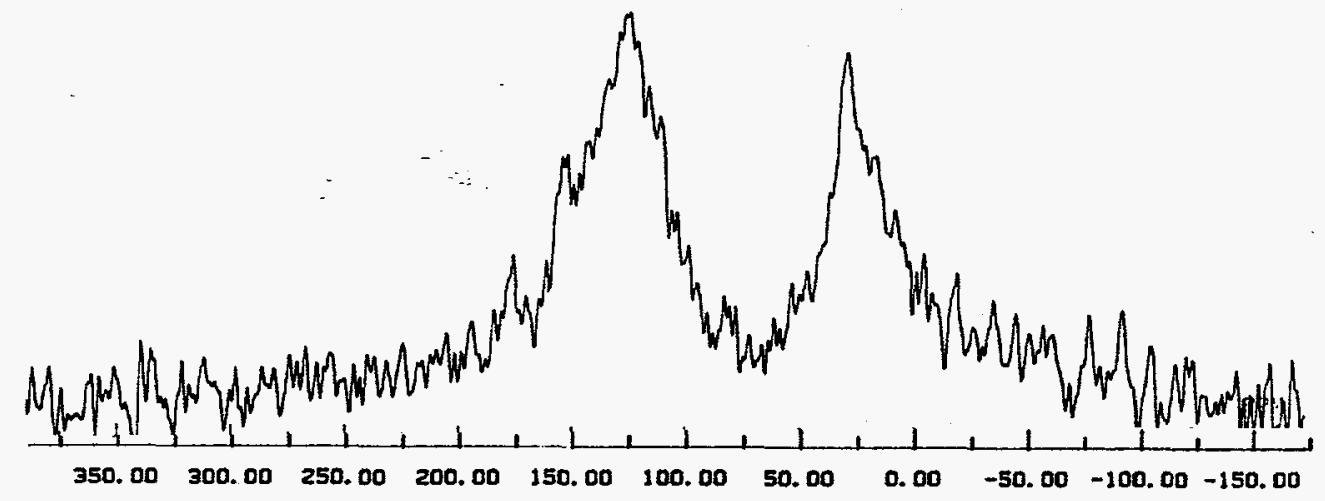

Chemical Shift, $\delta$ (ppm)

Figure A-1. Bloch decay ${ }^{13} \mathrm{C}$ NMR spectrum for DECS-1, subC "Bottom" seam, TX.

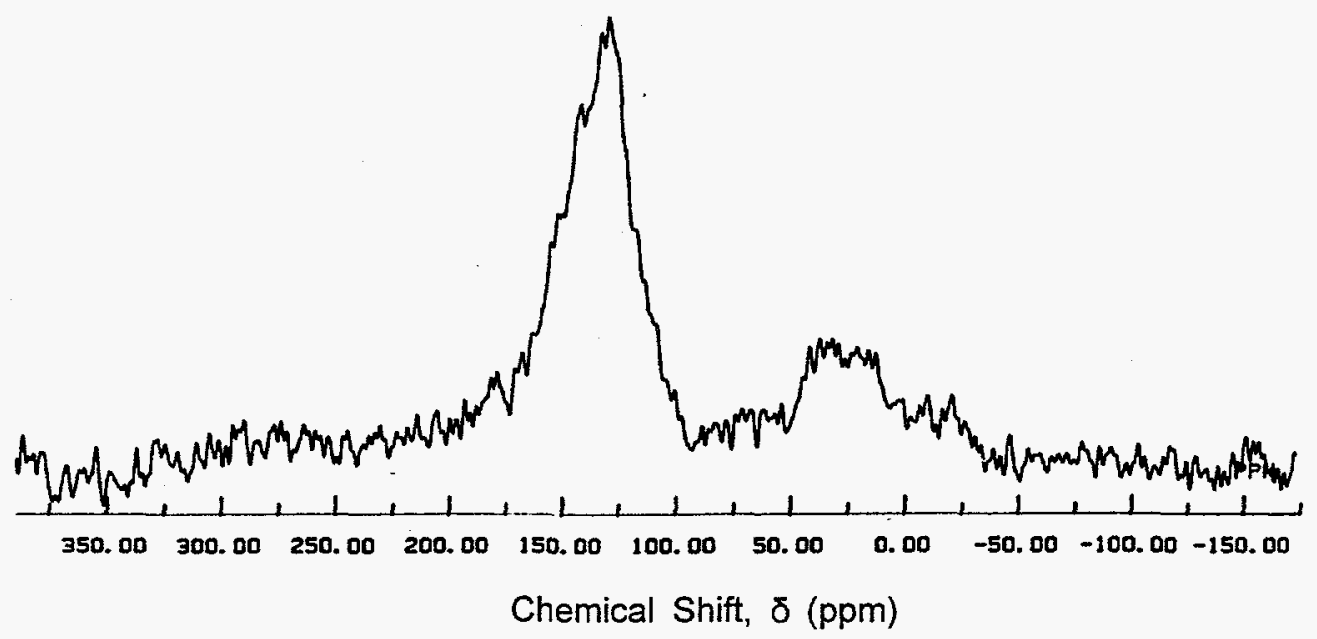

Figure A-2. Bloch decay ${ }^{13} \mathrm{C}$ NMR spectrum for DECS-2, hvCb Illinois \#6 seam, IL. 


\section{APPENDIX A. Bloch Decay NMR spectra}

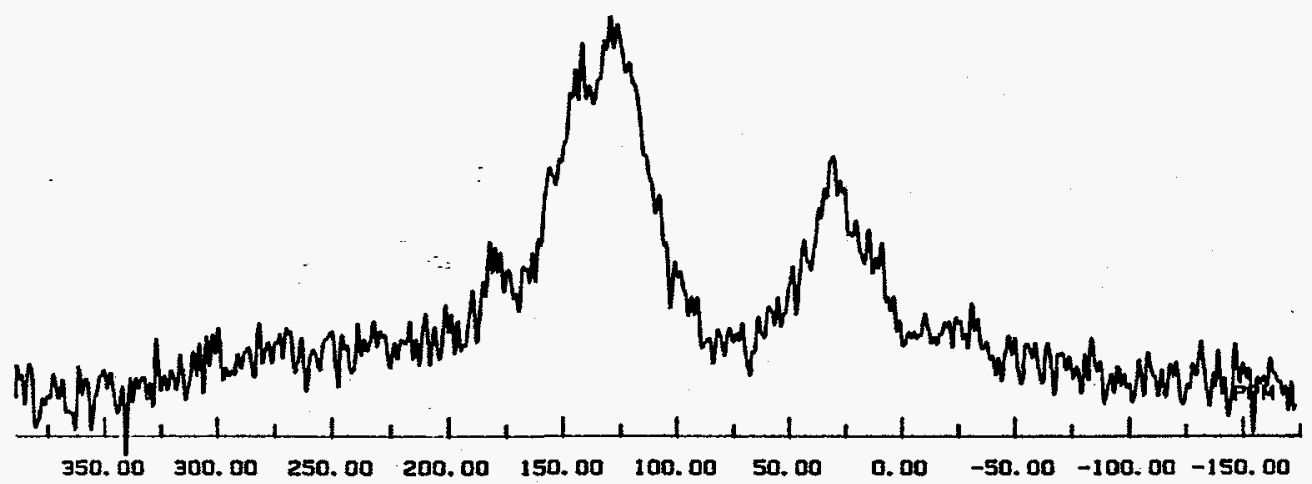

Chemical Shift, $\delta(\mathrm{ppm})$

Figure A-3. Bloch decay CPMAS NMR spectrum for DECS-8, subC "Wyodak" seam, WY.

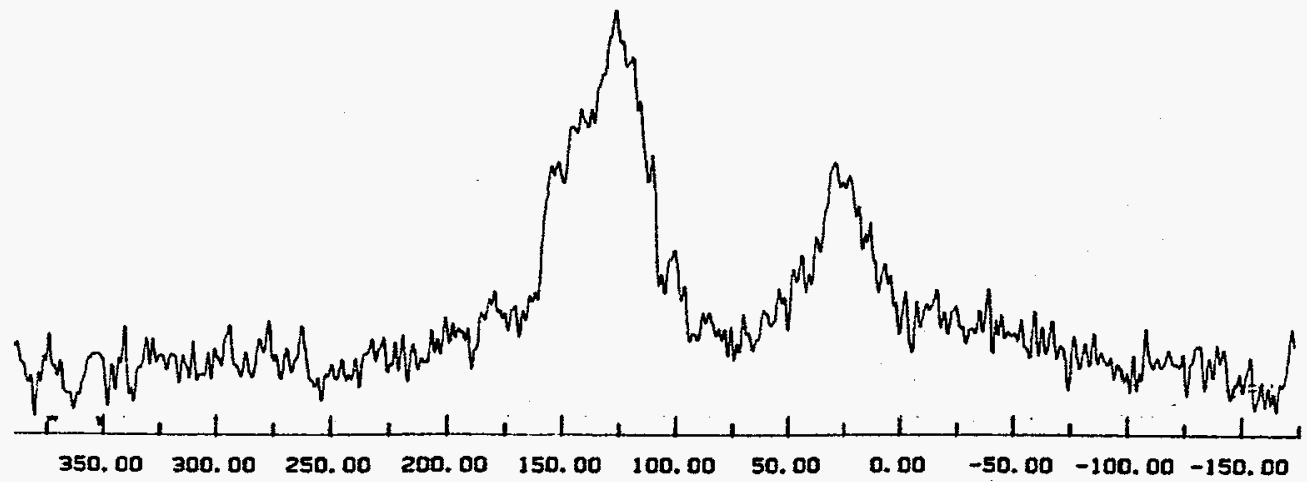

Chemical Shift, $\delta(\mathrm{ppm})$

Figure A-4. Bloch decay NMR spectrum for DECS-9, subB Rosebud seam, MT. 


\section{APPENDIX A. Bloch Decay NMR spectra}

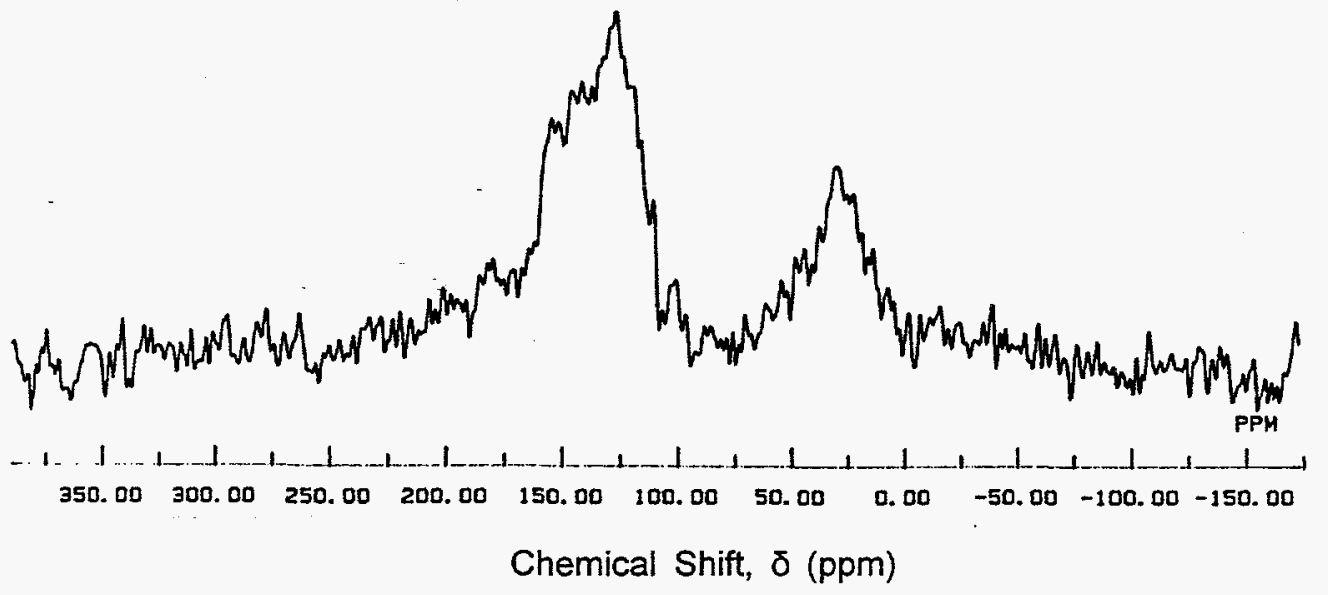

Figure A-5. Bloch decay CPMAS NMR spectrum for DECS-11, lig Beulah seam, ND.

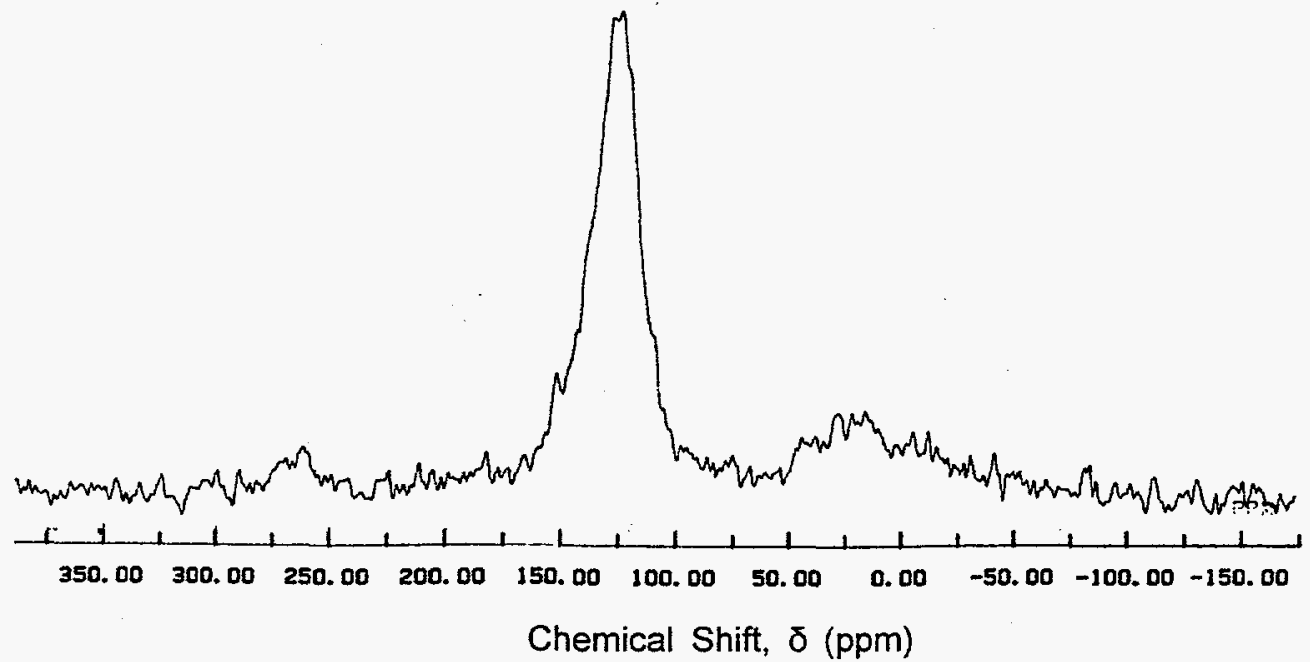

Figure A-6. Bloch decay NMR spectrum for DECS-13, mvb Sewell seam, WV. 
APPENDIX A. Conventional CPMAS NMR spectra

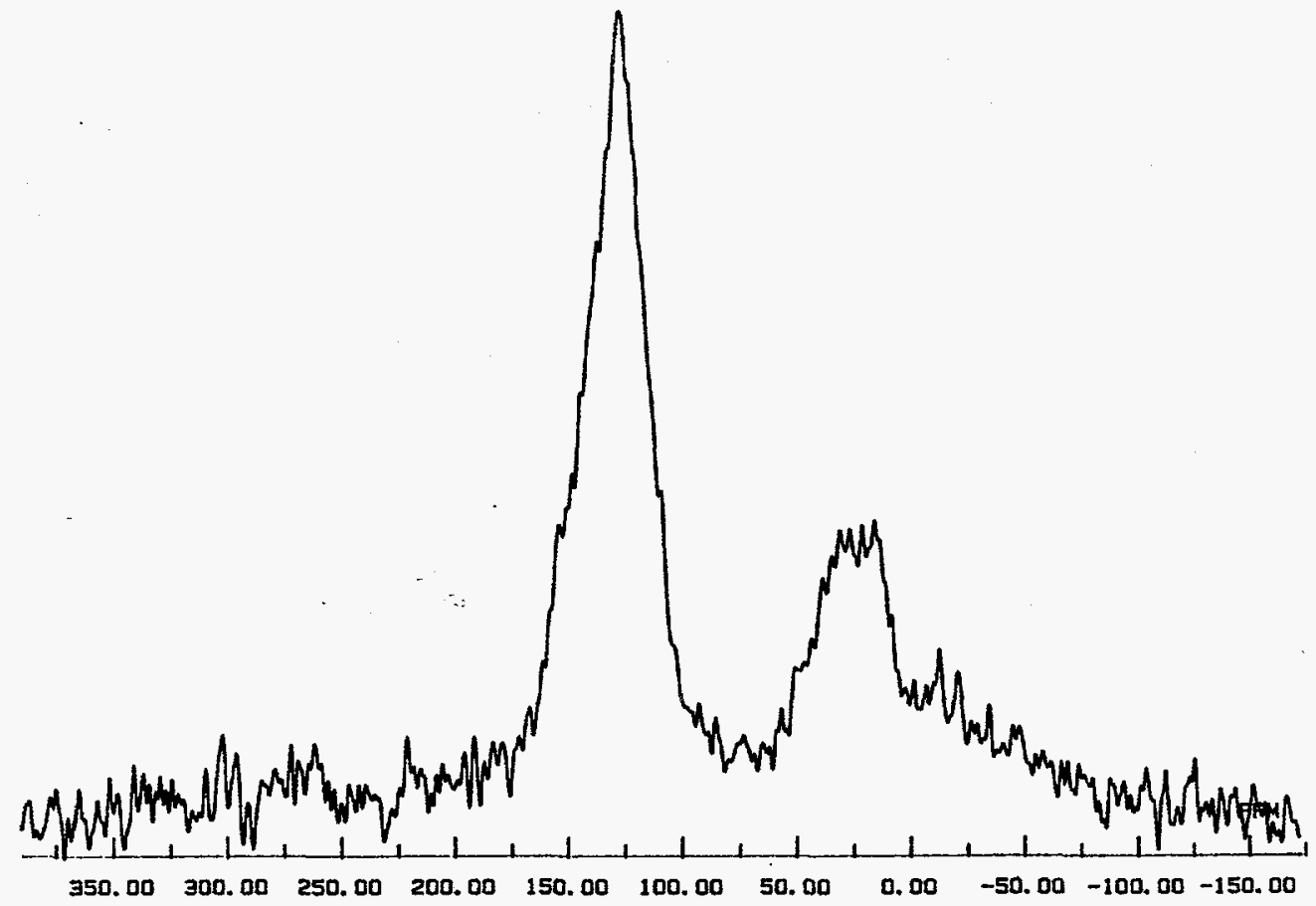

Chemical Shift, $\delta$ (ppm)

Figure A-7. Bloch decay NMR spectrum for DECS-18, hvBb Kentucky \#9 seam, KY.

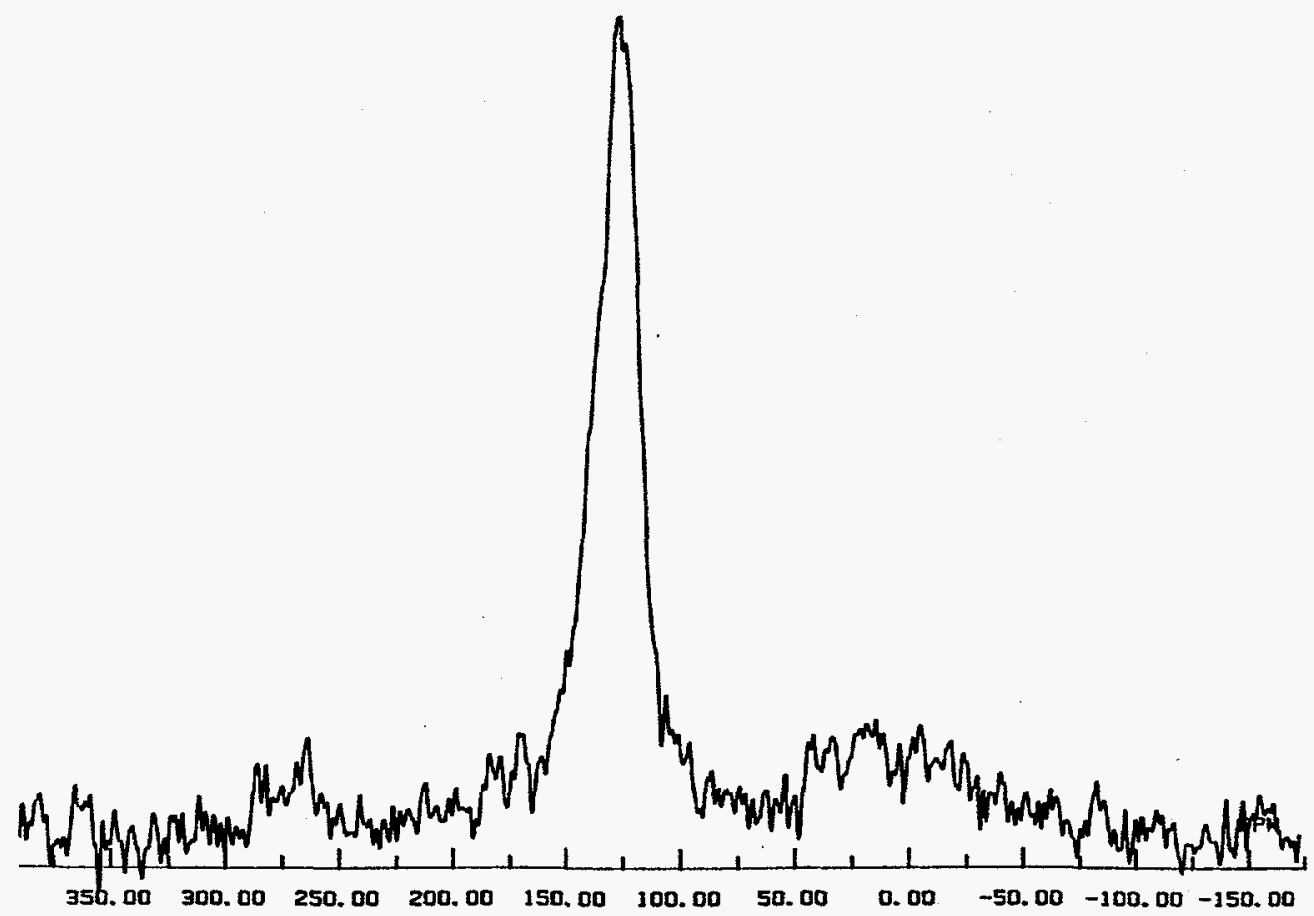

Chemical Shift, $\delta$ (ppm)

Figure A-8. Bloch decay NMR spectrum for DECS-19, Ivb Pocahontas \#3 seam, VA. 


\section{APPENDIX A. Conventional CPMAS NMR spectra}

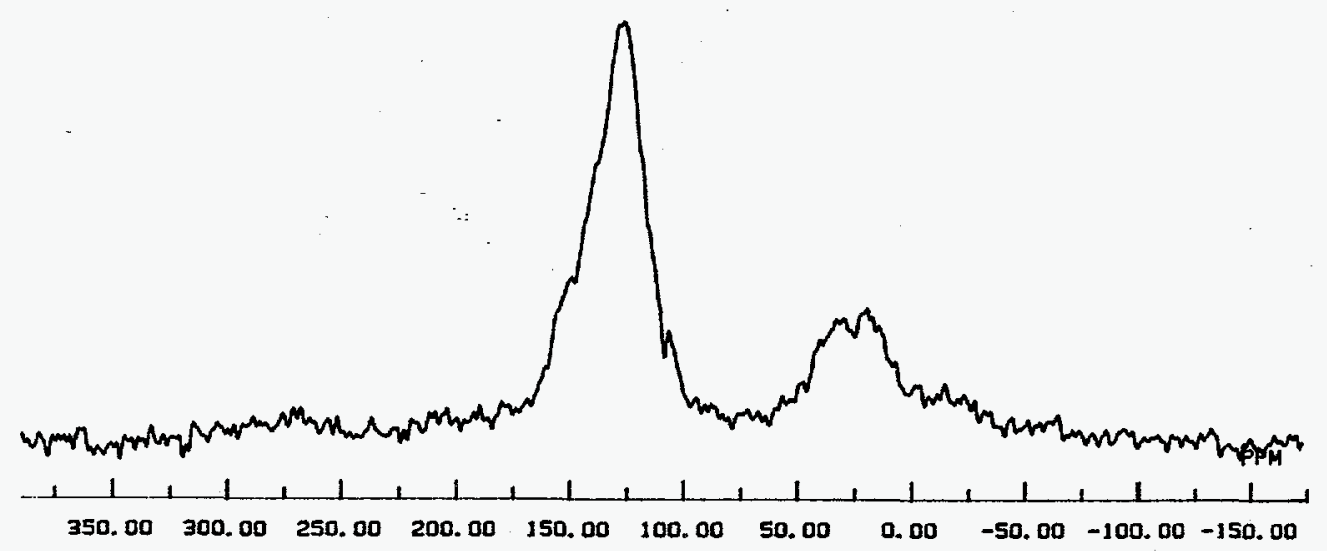

Chemical Shift, $\delta(\mathrm{ppm})$

Figure A-9. Bloch decay NMR spectrum for DECS-23, hvAb Pittsburgh seam, PA.

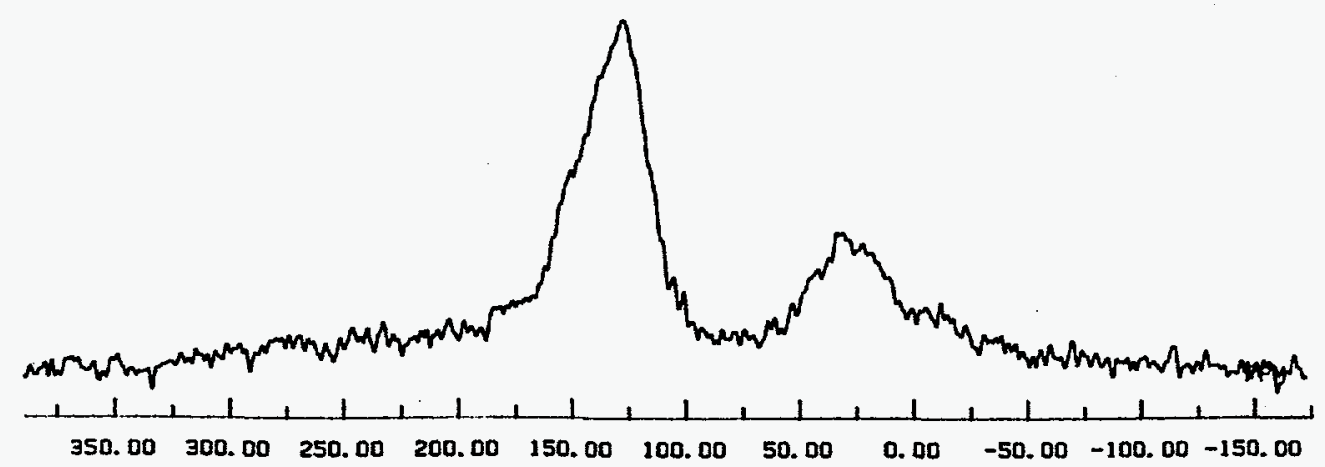

Chemical Shift, $\delta(\mathrm{ppm})$

Figure A-10. Bloch decay NMR spectrum for DECS-24, hvCb Illinois \#6 seam, IL. 


\section{APPENDIX A. Conventional CPMAS NMR spectra}

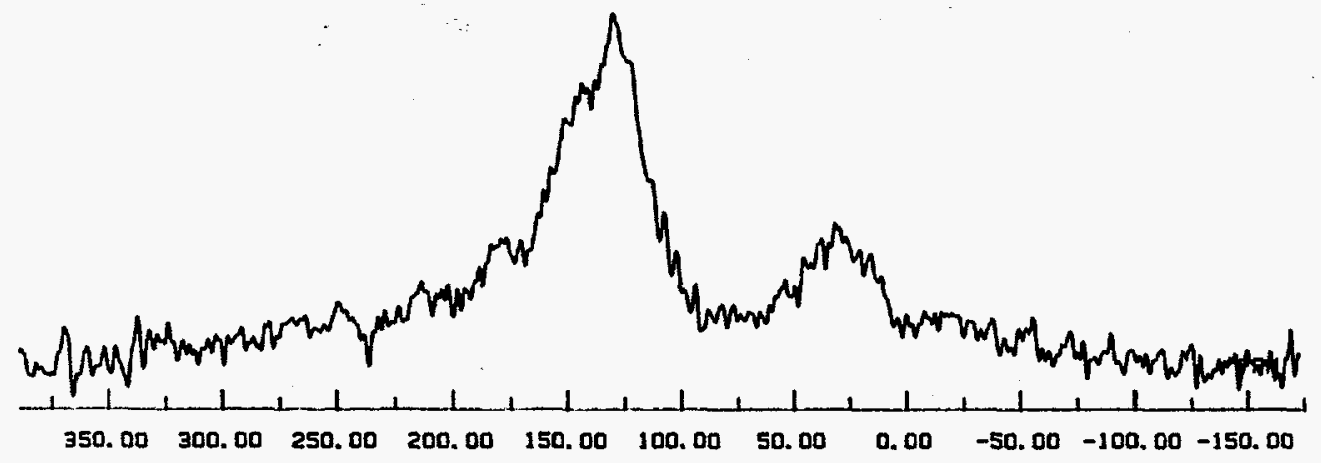

Chemical Shift, $\delta(\mathrm{ppm})$

Figure A-11. Bloch decay NMR spectrum for DECS-25, ligA Pust seam, MT

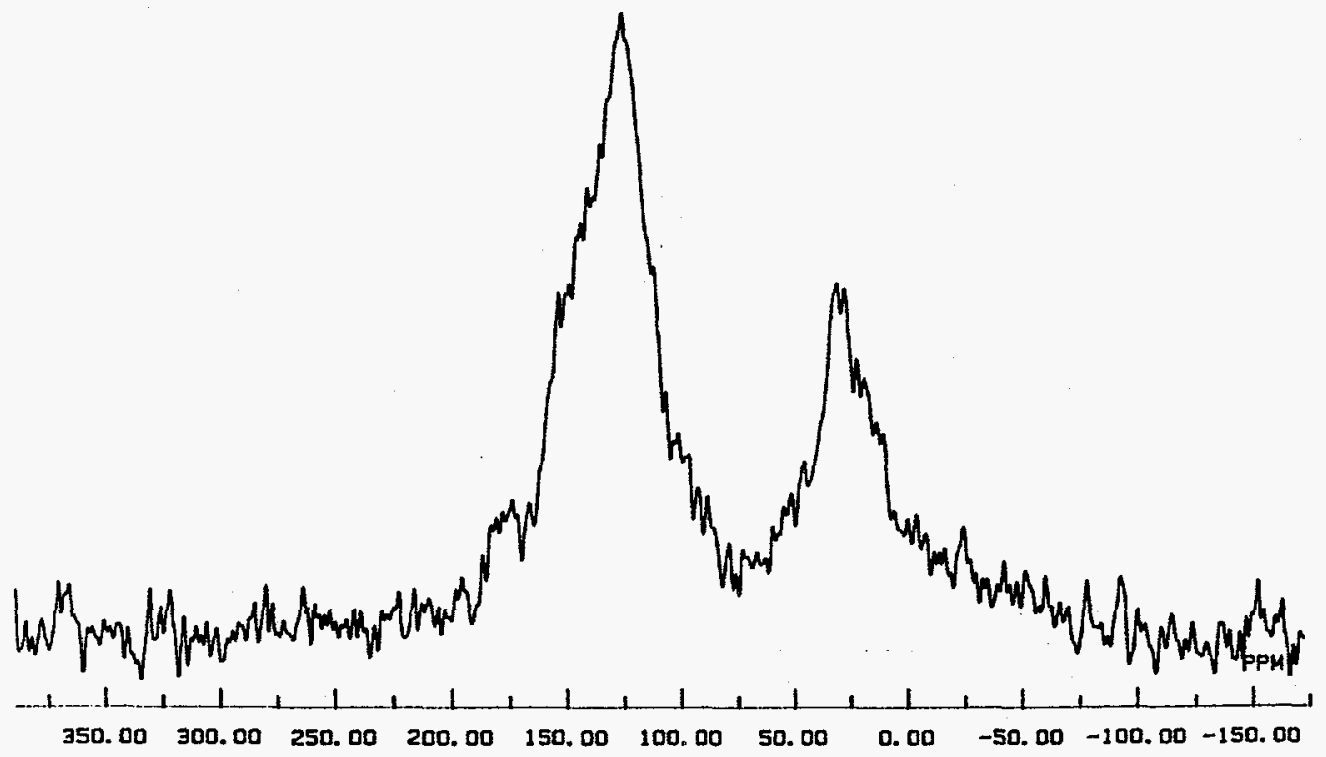

Chemical Shift, $\delta$ (ppm)

Figure A-12. Bloch decay NMR spectrum for DECS-26, subB Wyodak seam, WY. 


\section{APPENDIX A. Conventional CPMAS NMR spectra}

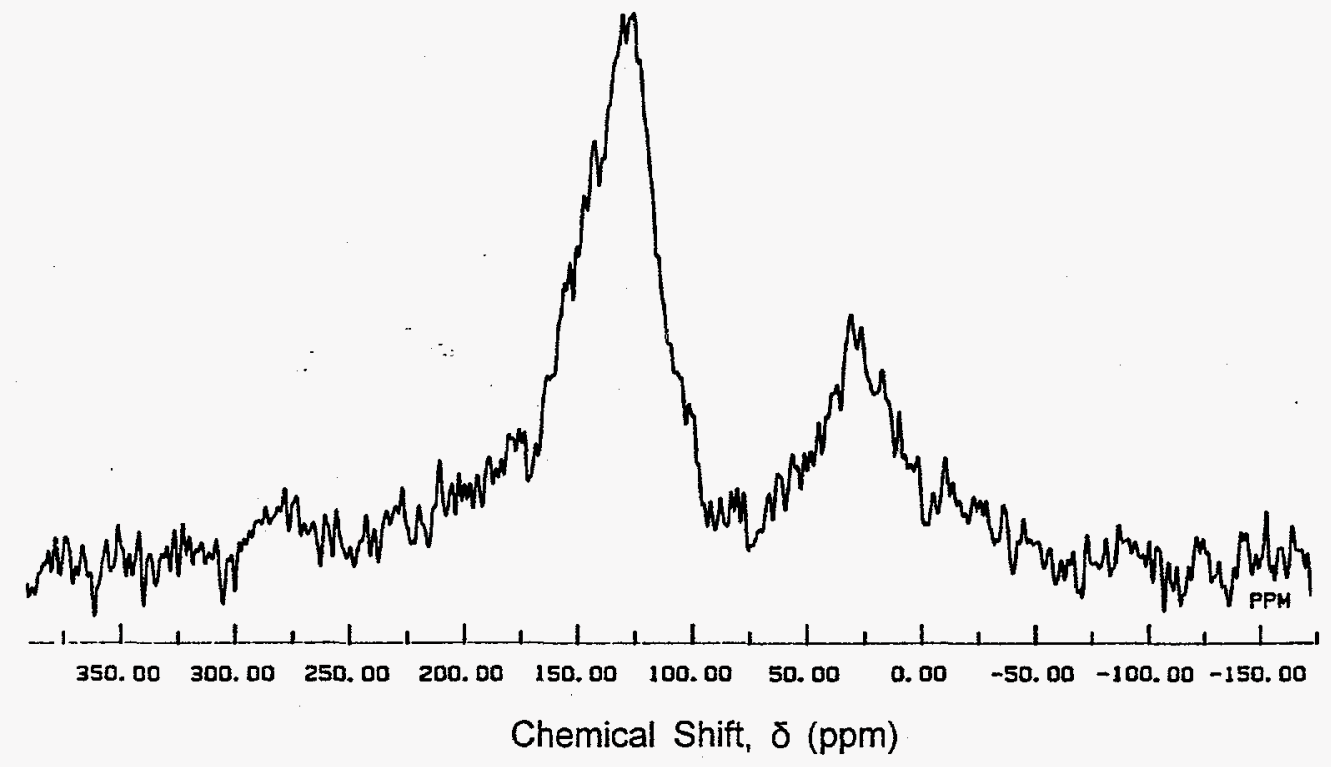

Figure A-13. Bloch decay NMR spectrum for DECS-27, subA Deadman seam, WY.

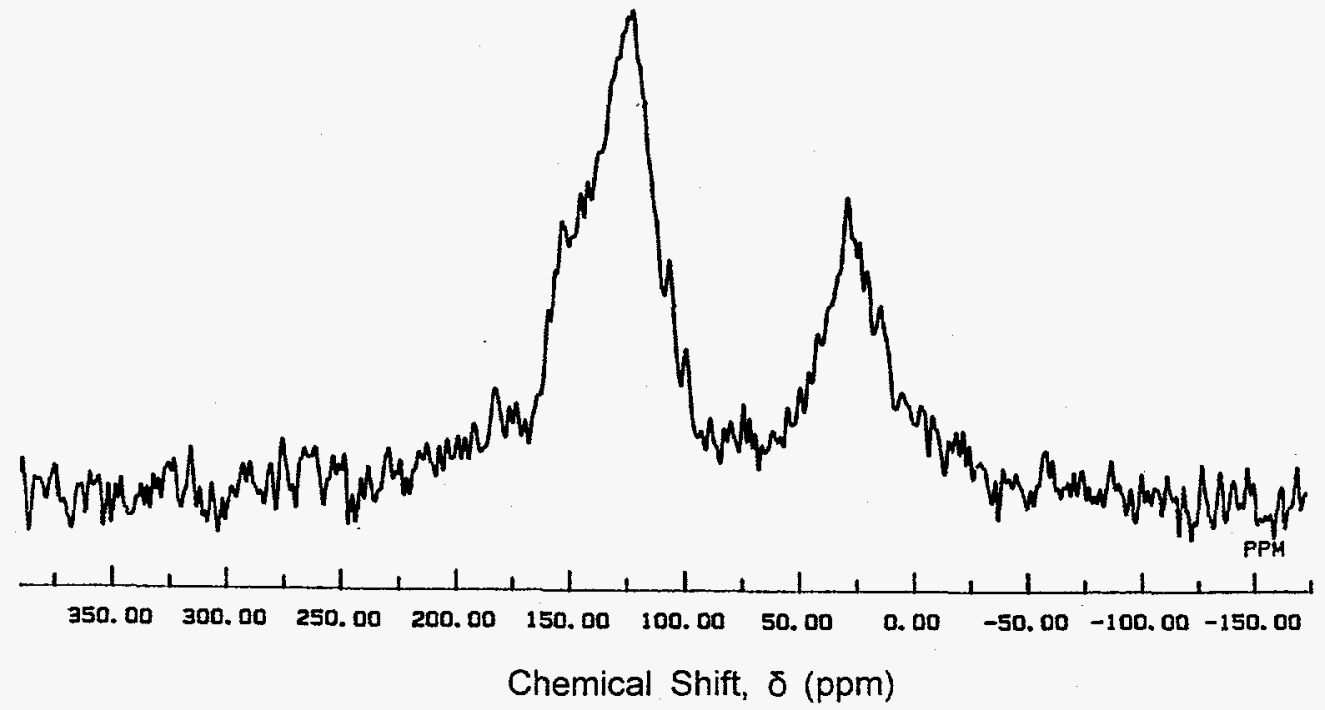

Figure A-14. Bloch decay NMR spectrum for DECS-28, hvCb Navajo seam, AZ. 


\section{APPENDIX B. Total ion chromatograms of pyrolyzates}

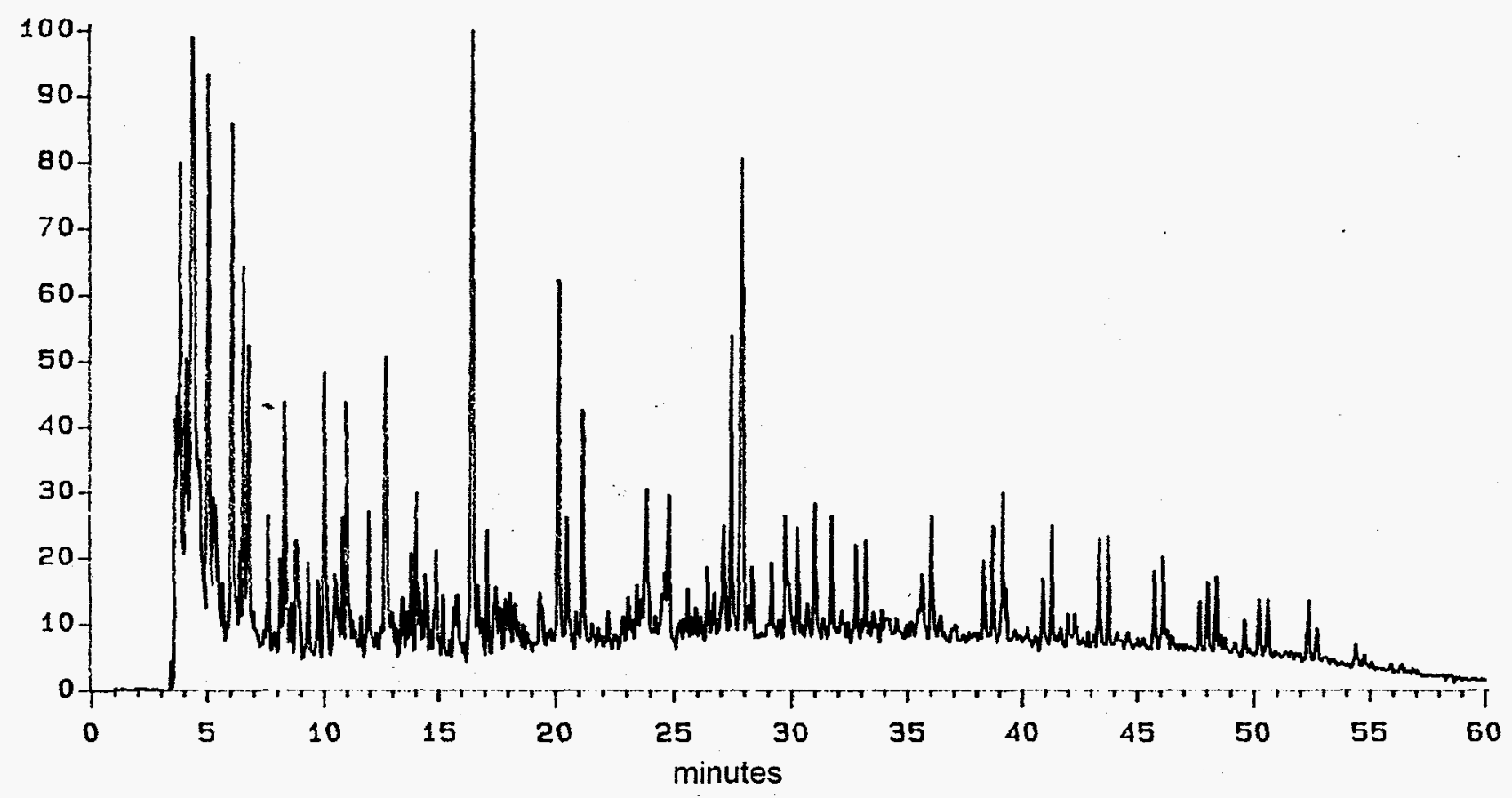

Figure B-1. Total ion chromatogram of pyrolyzates from DECS-1, subC Bottom seam, TX.

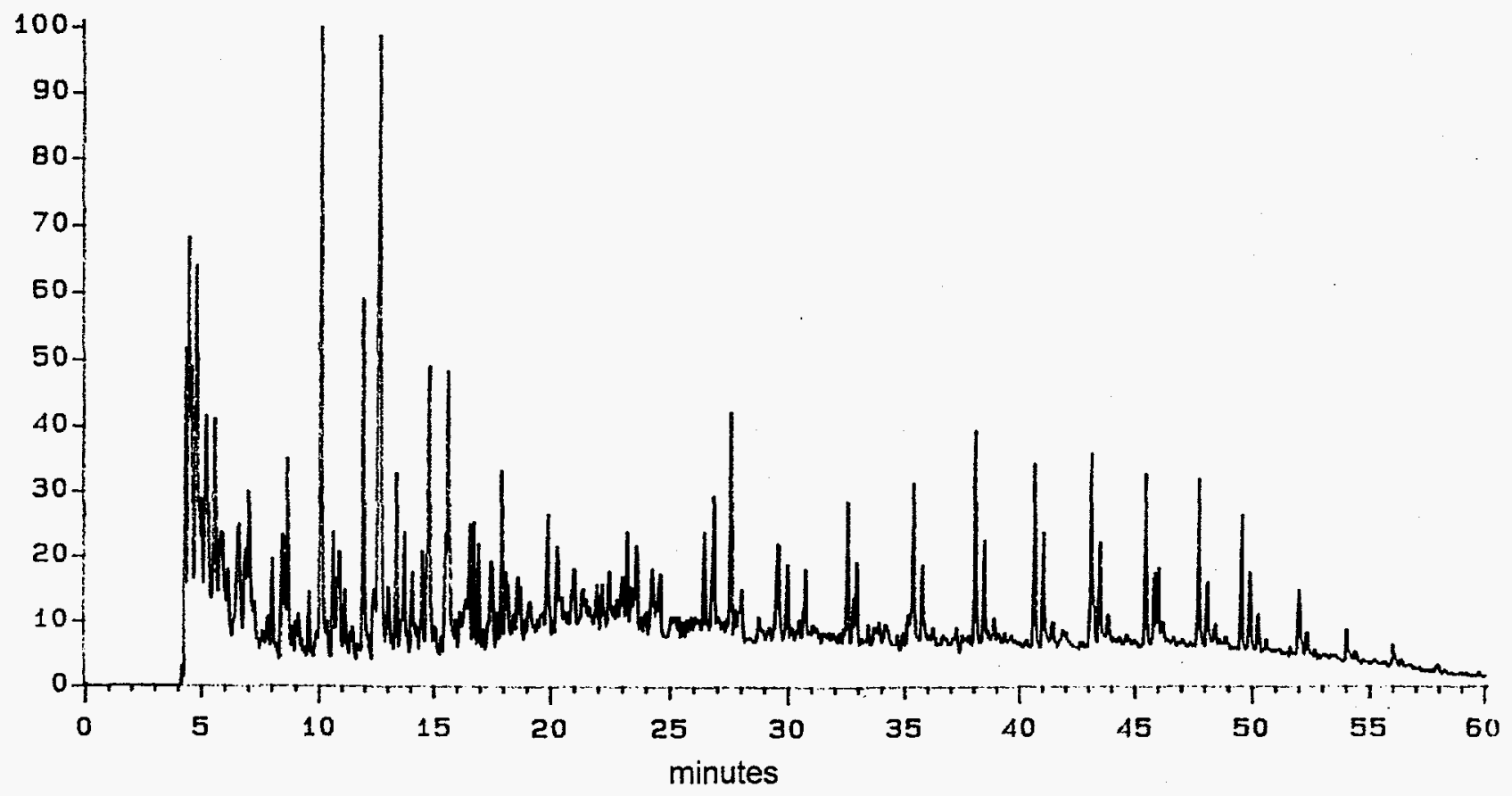

Figure B-2. Total ion chromatogram of pyrolyzates from DECS-9, subB Dietz seam, MT. 


\section{APPENDIX B. Total ion chromatograms of pyrolyzates}

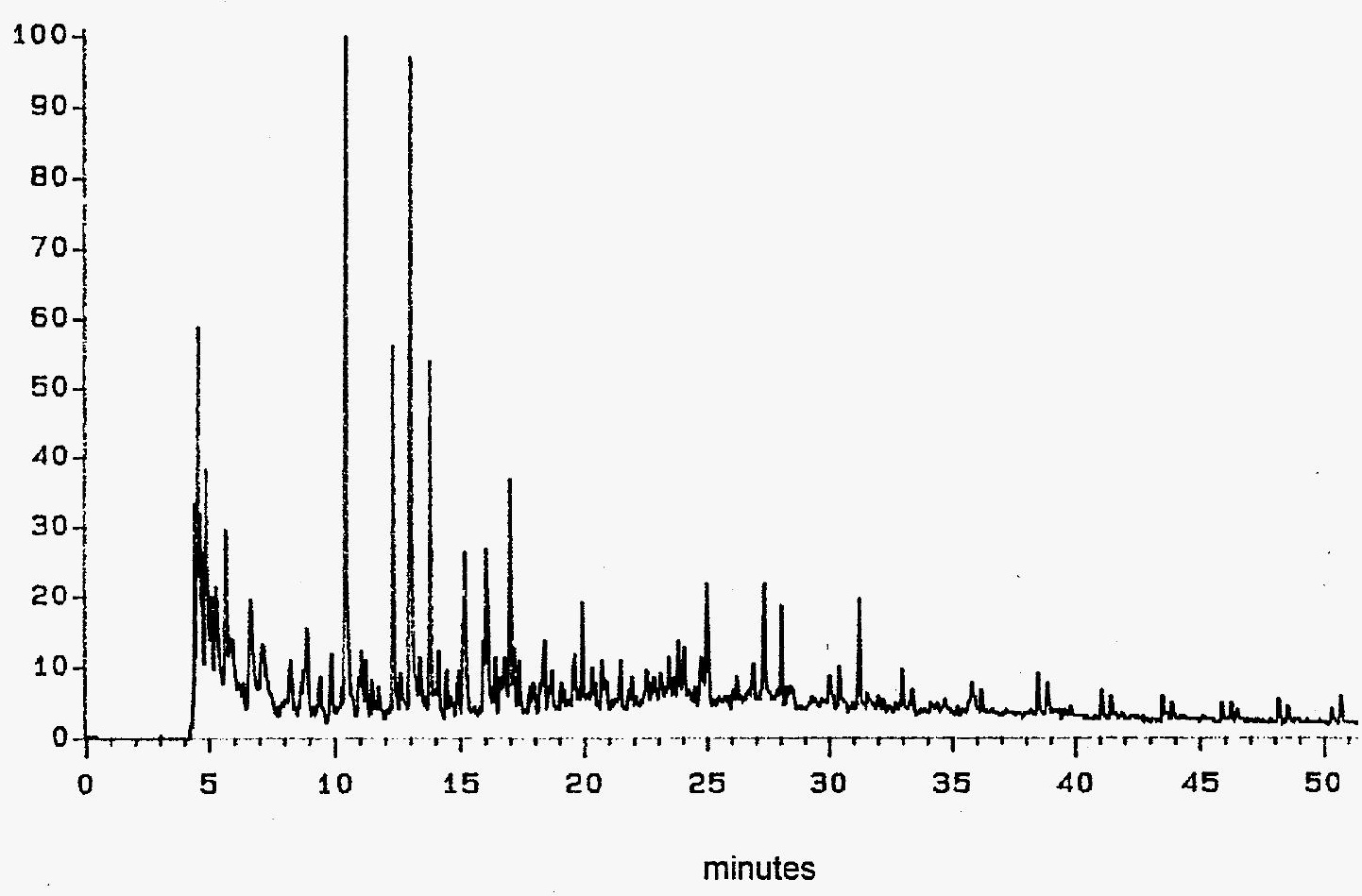

Figure B-3. Total ion chromatogram of pyrolyzates from DECS-11, ligA Beulah se

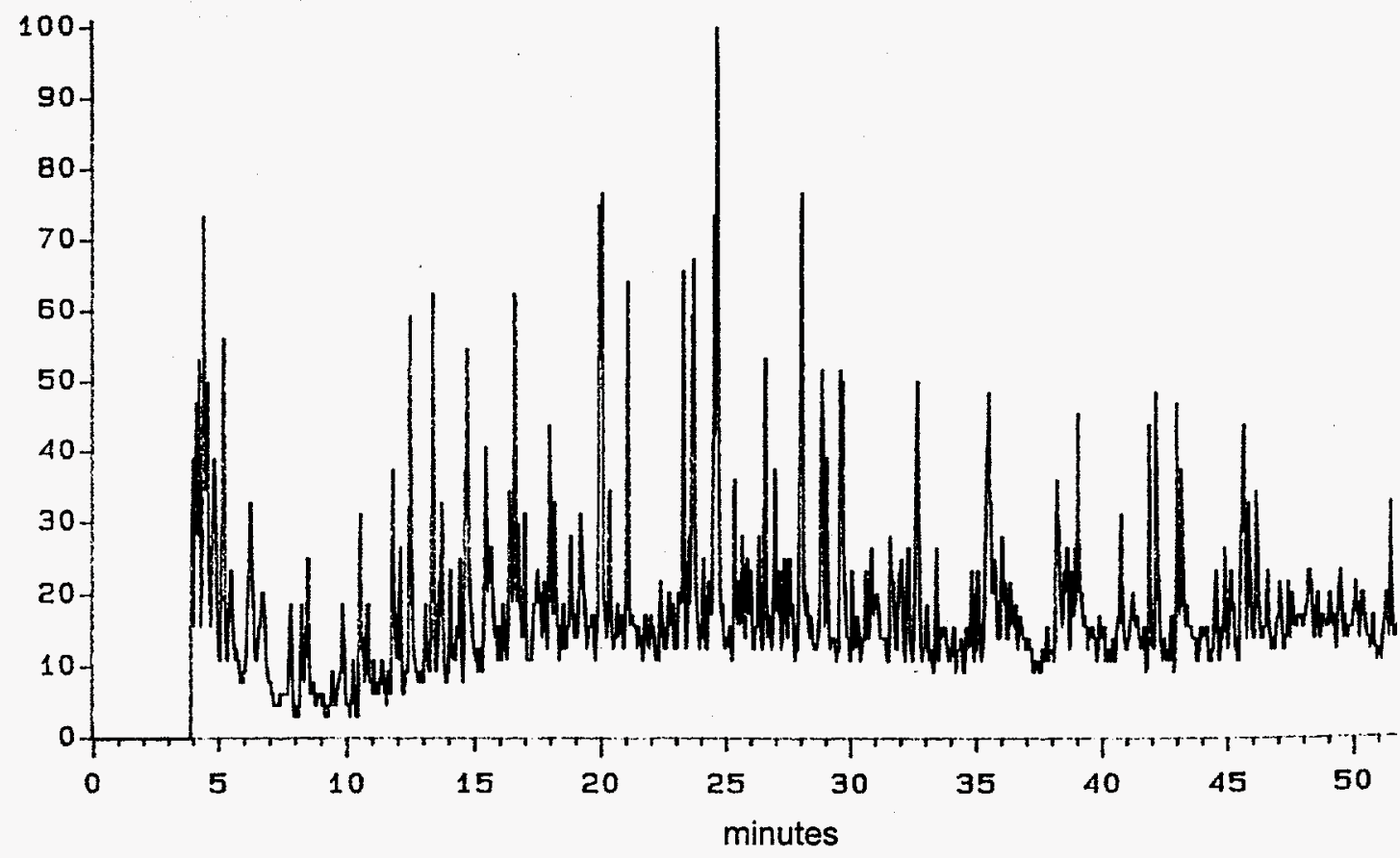

Figure B-4. Total ion chromatogram of pyrolyzates from DECS-13, mvb Sewell se 
APPENDIX B. Total ion chromatograms of pyrolyzates

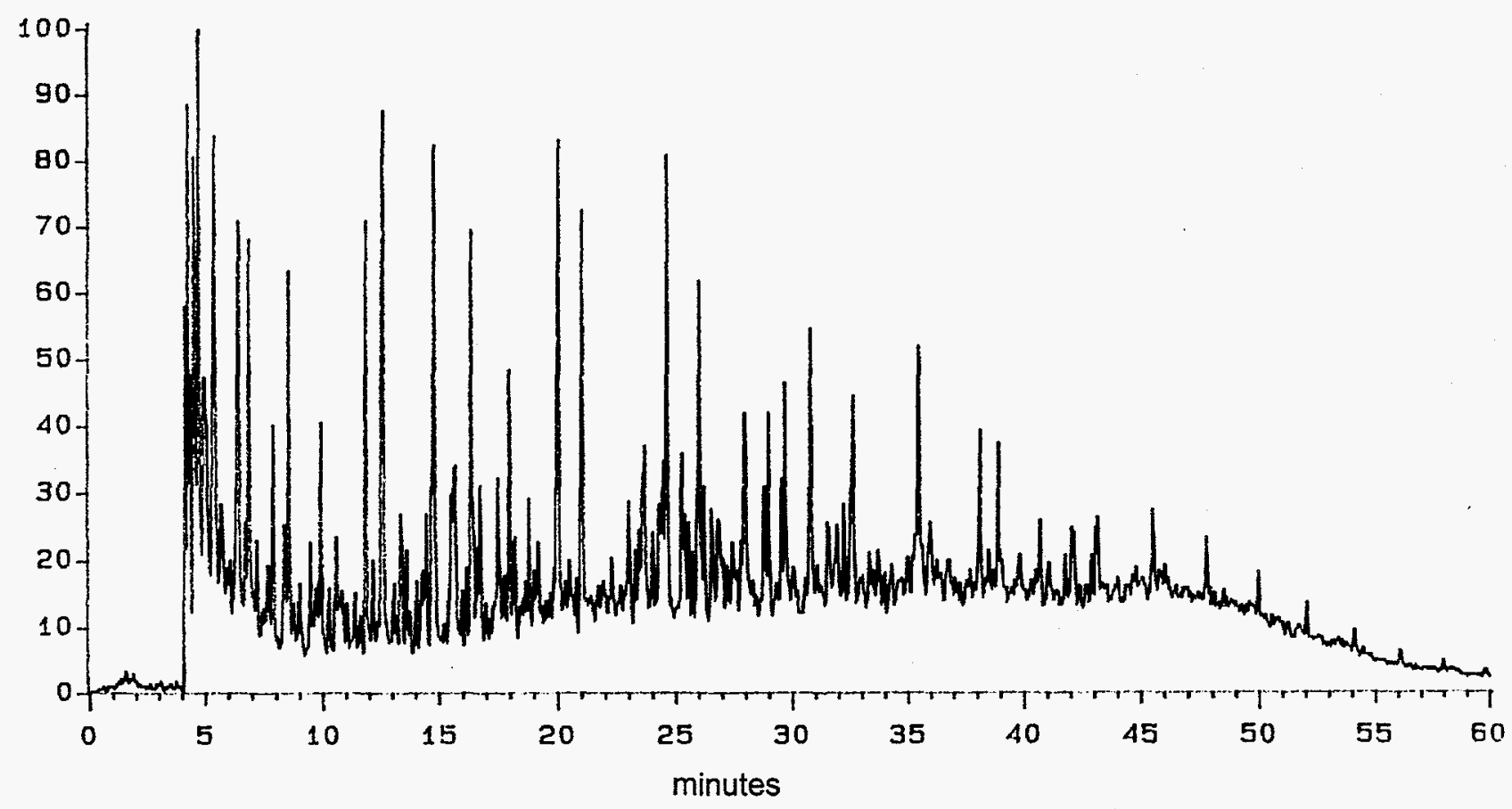

Figure B-7. Total ion chromatogram of pyrolyzates from DECS-23, hvAb Pittsburgh seam, PA. 